some six months ago in an important paper by M. Picque and M. Briand. They came to the conclusion that the surgeon should only interfere in cases of absolute urgency. M. Leredu, a barrister, sent in a report to the Society on the question formulated as follows :- "Is a surgeon within his rights in performing a surgical operation upon a lunatic without the consent of the patient's relatives ?" He answered in the negative, except in a case of absolute urgency. A lunatic is unable to give consent; it is his relatives who must give consent to the operation. But the relatives may refuse consent, possibly from fear of an unsuccessful result, or, on the other hand, with the deliberate wish to deprive a person who is a disgrace and expense to them of a chance of life. Again, the relatives may not choose to answer, or the lunatic may have no relatives. It is, then, the legislature that must be asked to supply an answer to the question. It would be easy to settle it by an enactment drawn in some such terms as these: "When a surgeon is of opinion that surgical interference is called for in the case of a person who is an inmate of a lunatic asylum, he shall obtain leave to operate from the relatives of the patient. In case the relatives refuse, the director of the asylum shall at once inform the Procureur of the Republic. This official shall put the tribunal in possession of the facts, whereupon it may rule the case to be one of urgency and the proposed operation to be a last resource, making the order in the Chambre de Conseil, after having referred the matter, should it think fit, to medico-legal experts for an opinion as to the propriety of surgical intervention." M. Picque, in supporting the opinion of $M$. Leredu, showed how difficult it was to obtain a really valid consent from relatives. In twenty cases where he applied for leave he received but one answer. The disagreeable consequences (which may arise to a surgeon through operating without consent) being taken for granted, M. Picque would only dispense with such consent in the three following instances: suffocation, strangulated hernia, and arterial hæmorrhage. There might be others, such as metrorrhagia and conditions associated with the urinary organs, but so long as the matter was not settled, either by statute or by a resolution of the Society, he would not interfere, unless he had some authorisation in writing, for fear of incurring both moral and material responsibilities, which in France were very grave. If the patient were to die his relatives, who had shown themselves absolutely indifferent when permission was asked of them, would not hesitate to claim damages and to attack the surgeon in the public prints. Even if the operation were successful the surgeon would not be free from the risk of disagreeable consequences. In the discussion which followed, without any conclusion being then arrived at, it was curious to see the legal members, among whom was M. Jacobi, the Advocate-General, giving their opinion that it was right for the surgeon to operate if he thought it necessary, even against the wishes of the relatives, while the medical members were less bold and demanded some legal protection to cover their responsibility. As a matter of fact, despite the philanthropic and philosophic views of individual members of the magistracy, the medical profession know only too well how of late these very magistrates have, when sitting in court, shown themselves both severe and unfair towards medical men, and how ready they are to entertain complaints from the relatives of patients against their medical advisers.

\title{
Wounded Soldiers in Scotland.
}

We note that the Board of Directors of the Crichton Royal Institution, Dumfries, have offered to accommodate ten wounded soldiers from South Africa, preferably men suffering from nervous disorders.

\section{AFTER-CARE ASSOCIATION.}

The annual meeting was held on February 19th, at the house of Dr. Blandford, who presided. The Chairman, in his introductory remarks, pointed out that the main object of the Association was to help those who had left asylums recovered from an attack of insanity to make a fresh start in life; and this was the more necessary as mental illnesses were often matters of months, not days or weeks, and consequently situations could not be kept open for the sufferers, as they were some- 
times for hospital patients. The Secretary (Mr. Thornhill Rexby) then read the annual report, from which it appeared that, during 1899,222 cases had been before the council, the largest annual number ever dealt with. Cases had been assisted, as in the past, by being boarded out in cottages in the country, by grants of money, and by finding occupation. The investigations involved had been of an onerous character. The failures had been comparatively few. Boards of guardians had availed themselves largely of the help of the Association, and in some few cases they had subscribed to its funds. The total amount of subscriptions, donations, and contributions for maintenance was $65498 s$. I $d$., a falling-off from the previous year, when they amounted to 6652 . In moving the adoption of the report, $\mathrm{Dr}$. G. H. Savage remarked on the difference between hospital and asylum patients, and the usefulness of such a society to bridge the gulf (too often exaggerated by popular prejudice) between "alienism" and the ordinary conditions of social life. The Association had done valuable work in two directions - in confirming health, and in preventing relapse. The resolution was seconded by the Rev. Dr. Springett (Vicar of Brixton), who bore personal testimony to the admirable character of the agencies employed by the Association, and having been supported by the Rev. W. St. Hill Bourne and by Dr. Shuttleworth, was carried unanimously. Dr. Percy Smith moved, and $\mathrm{Mr}$. Deputy White seconded, the reappointment of the council and officers of the Association, and the meeting concluded with a vote of thanks to the Chairman, moved by the Rev. Henry Hawkins, and seconded by Dr. Rayner. The offices of the Association are at Church House, Dean's Yard, Westminster, S.W.

\section{HABITUAL DRUNKENNESS.}

The Inebriates Act of 1899 was passed just before the close of the session to remedy a defect of the Act of the previous year. But, although it has been remedied in regard to the expenses of prosecution, complaints are made by magistrates that it is practically a dead letter, and the Home Secretary has admitted that the accommodation provided is insufficient.

\section{NEW SOUTH WALES BILL.}

The New South Wales Bill, introduced by the Hon. Dr. J. M. Creed, passed the Legislature Council, and has been presented to the Legislature Assembly. The main provisions show an advance upon what has been done in this country. Under this Bill it is lawful for a judge or magistrate or the master in lunacy, and after the evidence of a medical practitioner and on inspection, to make an order as to the control of an inebriate.

On the application of-

(a) An inebriate or any person authorised in writing on that behalf by an inebriate while sober :

(b) The husband, or wife, or a parent, or a brother, sister, son, or daughter of full age, or a partner in business of an inebriate; or

(c) a member of the police force of or above the rank of sub-inspector acting on the request of a duly qualified medical practitioner in professional attendance on the inebriate, or on the request of a relative of the inebriate, or at the instance of a justice of the peace-

to order that the inebriate be placed under private or public treatment for a period not exceeding twenty-eight days; or be placed in a licensed institution for such period not exceeding twelve months, as may be mentioned in the order; or that the inebriate be placed for any period not exceeding twelve months, to be mentioned in the order, under the care and charge of an attendant or attendants to be named in the order, and who shall be under the control of the judge, master in lunacy, or magistrate making the order. ${ }^{\circ}$.

Where an inebriate has thrice within the preceding twelve months been convicted for an offence of which drunkenness is a necessary ingredient, it shall be lawful for any Court of Petty Sessions to order that the inebriate be placed for such period of not less than six or more than twelve months, as may be mentioned in the order, in any institution which may be established by the Government for 